\title{
UN RÍO QUE NACE FRADE E MORRE BISPO OU NACE BISPO E MORRE FRADE. APUNTAMENTOS SOBRE O PATRIMONIO CULTURAL HIDRAULICO GALEGO
}

Francisco Alonso Toucido Grupo de investigación Síncrisis (USC) Estela Arqueoloxía e Patrimonio S. L. 

No país dos mil ríos, o ser humano condicionou en gran medida, nun momento máis ou menos próximo a nós, a paisaxe que xeralmente entendemos como natural. Os ríos, dada a súa importancia no tocante aos recursos alimentarios, enerxéticos, industriais e de transporte, non son alleos a este feito. Un bo exemplo disto é o condicionamento antrópico en moitos ríos galegos nos que o último punto que acada a auga salgada do mar, na súa desembocadura, é algún tipo de estrutura realizada polo ser humano, como unha represa de pesca, uns pasos ou, no río Lérez, o encoro de captación de auga de Bora.

O uso continuo dos ríos por parte da sociedade ao longo da historia, así como as peculiaridades do seu sistema de poboamento, do seu sistema agrario tradicional e do seu devir histórico, permítenos contar con ríos cheos de patrimonio, tanxible e intanxible.

Se consultamos un visor de planificación urbanística de Galicia como o Plan Básico Autonómico, na súa capa de ríos podemos observar a alta densidade de cursos fluviais que existen, ademais das súas áreas de protección desde a perspectiva da xestión da auga. No entanto, estas áreas agochan tamén un patrimonio rico e singular que esmorece.

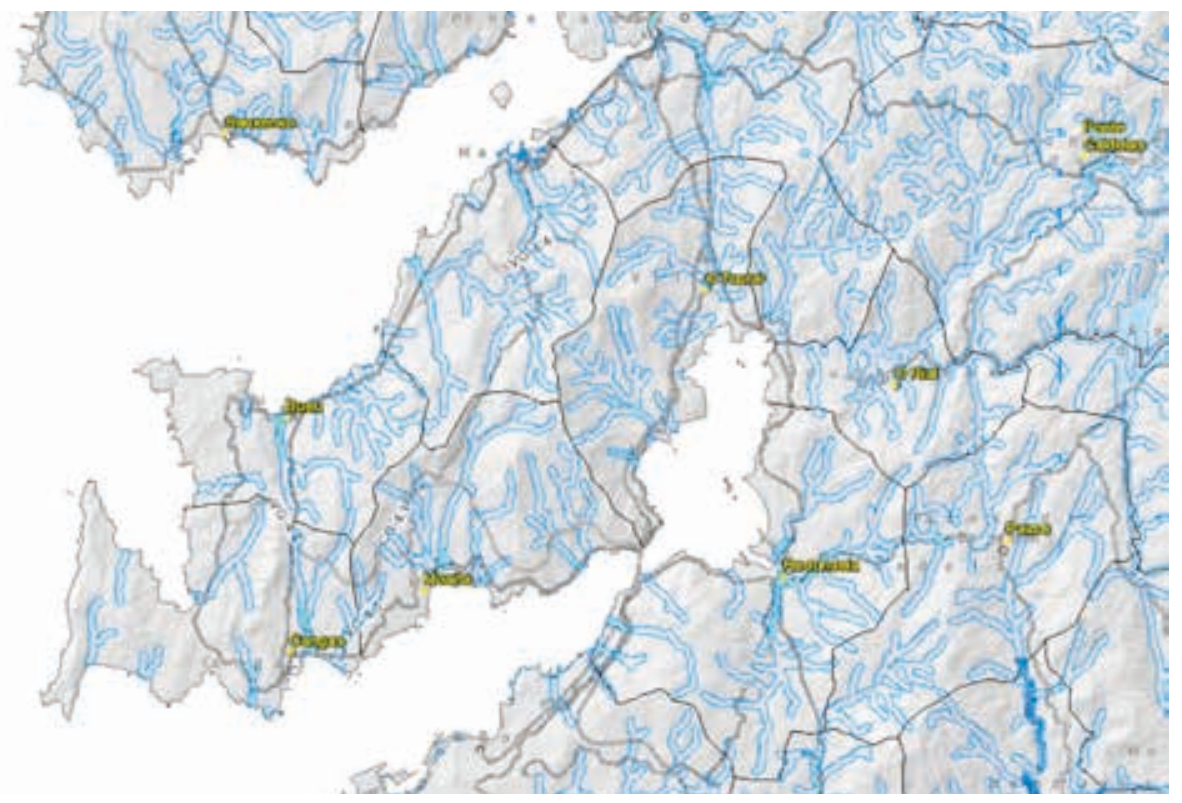

Áreas de protección dos cursos fluviais do Morrazo. Fonte: PBA Xunta de Galicia 
Os ríos son custodios de obras de auténtica enxeñaría popular. Os construtores de pontes tradicionais, canles de rego, levadas e muíños eran auténticos enxeñeiros sen titulación. Poñamos por caso un dos patrimonios hidráulicos máis recorrentes: os muíños. Adoitamos contemplar cada un deles sen ter en conta o seu contexto e as difíciles condicións da contorna nas que foron edificados. Non somos conscientes dos seus sistemas de captación, xa que os muíños acostuman levar a auga desde moitos metros río arriba cunha correcta inclinación e estas levadas aliméntanse de presas necesarias para desviar a auga e devolverlla máis adiante ao río ou ao seguinte muíño a través dos infernos.

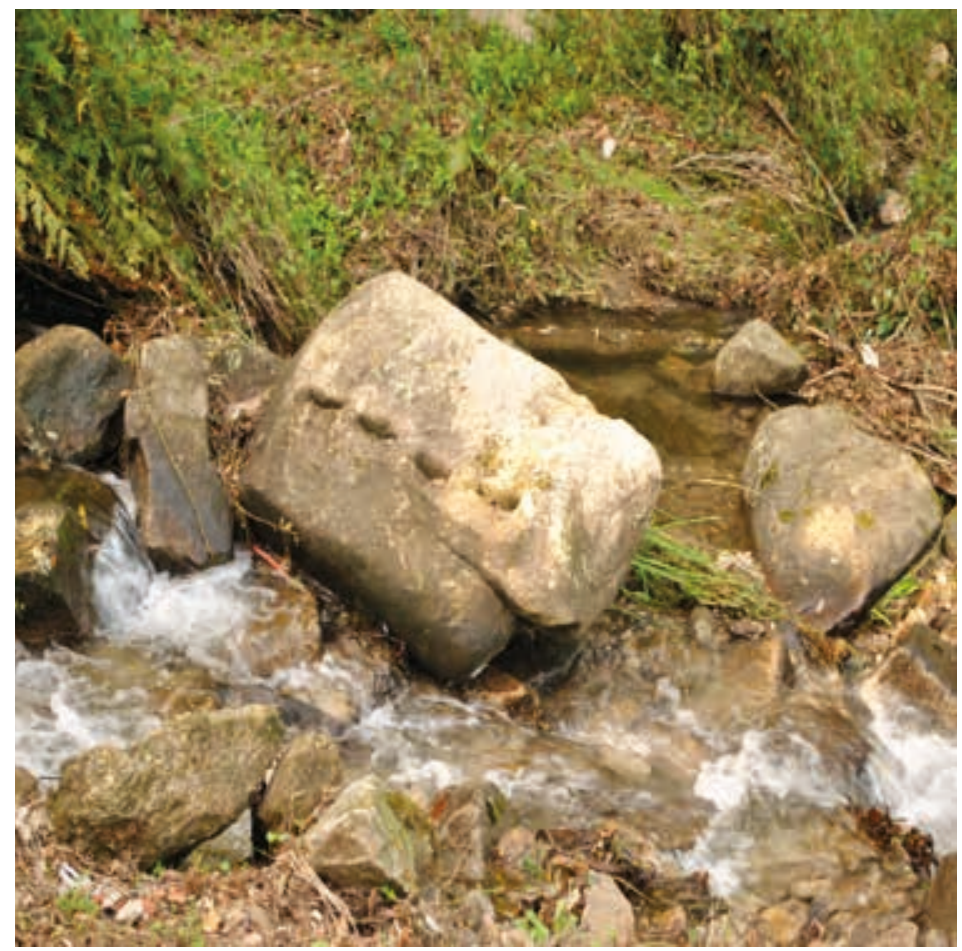

Traballos de cantaría nos muíños do Batán, en Salcedo (Pontevedra)

Estas obras de enxeñaría popular son tanxibles, pero, cando nos achegamos a un río, outro dos aspectos dos cales non adoitamos ser conscientes desde o punto de vista patrimonial é o seu patrimonio inmaterial e o que no río implica, é dicir, a multitude de lendas, anécdotas e vivencias ao redor del. 
O uso intenso ao que eran sometidos os muíños pola necesidade de contar sempre con fariña fresca para facer pan; o sistema de posesión e herdanza de moitos muíños, repartidos entre varias familias; as zonas de lavado e clareo de roupa no río, ou as zonas de tratamento do liño e de pesca converteron os ríos e os seus camiños de servidume en auténticos espazos públicos, percorridos por numerosas persoas ao longo de varias xeracións, tanto durante o día coma á noite, cando moitos muíños debían continuar moendo para dar a suficiente produción aos seus propietarios.

A comprensión do río como un espazo máis da paisaxe tradicional, pero moito máis frecuentado ca outras zonas da propia paisaxe, provoca que se xeren multitude de lendas e tradicións arredor da súa figura. Por exemplo, por mencionar un caso entre milleiros, a tradición da ponte da Senra, en San Cibrán de Ribarteme (As Neves), segundo a cal unha muller cun embarazo difícil debía colocarse baixo a ponte mentres dous familiares facían garda na zona superior para dar conta dos primeiros home e muller que pasasen, que se converterían nos padriños do neno. Se isto se cumpría, o parto iría ben, mais se os familiares non eran quen de controlar o paso dun can ou outro animal pola ponte, a muller abortaría.

Os ríos galegos son espazos de tradición e moito traballo, mais tamén espazos de troula, por mor da cantidade de noites pasadas a moer no muíño. Así o testemuñan numerosas coplas e a máis ca probable orixe da muiñeira, asociada a estas troulas.

Porén, os usos e tradicións que vimos de referir son propios dunhas sociedades cunha realidade agrogandeira e vinculada coa paisaxe dunha maneira moi diferente á sociedade actual. As estampas destes muínos en uso, así como as do río como un dos espazos máis transitados e empregados da parroquia, xa quedaron para o recordo e os libros de historia. Este rico patrimonio esmorece, física e inmaterialmente; fisicamente ante o abandono dos usos agrícolas tradicionais, con multitude de muínos caídos en desuso sen alguén que os traballe e, por tanto, os manteña ou tamén, desde unha perspectiva hidráulica, dadas as numerosas destrucións derivadas da xestión das administracións públicas. Cada vez son menos os lavadoiros en uso, máis os pasos e pontellas destruídos e moitos menos os muínos con capacidade de moer, como tamén cada vez son menos as persoas con recordos dos usos destes espazos hidráulicos tradicionais, das súas lendas, a súa toponimia etc., debido ao proceso de avellentamento e despoboamento do rural. 
Así e todo, co patrimonio hidráulico prodúcese unha situación interesante tendo en conta que as políticas de xestión integral do patrimonio dos concellos, no tocante á conservación e divulgación, son en moitos casos inexistentes. Os muíños e outros elementos hidráulicos coma os lavadoiros sempre tiveron unha posición privilexiada. Son numerosas en toda Galicia as obras de rehabilitación de muíńos, troco de cubertas, restitución de muros, arranxo de pontellas e lavadoiros, creación de sinalética e infraestrutura interpretativa a carón dos ríos etc.

Un exemplo significativo son os múltiples obradoiros de emprego dedicados aos traballos de mellora ou recuperación de muíños, que adoitan deixalos coas cubertas novas e a pedra totalmente limpa. Prima unha hipotética rehabilitación dun elemento que, en estado de ruína, fosiliza o abandono da paisaxe tradicional e os trocos históricos da nosa sociedade, dáse prioridade á súa recuperación óptima fronte a unha consolidación da ruína que podería explicar e evidenciar cambios sociais e históricos complexos e próximos a nós. Ambas as situacións son importantes, tanto o uso dos muíños coma o seu abandono, e non debería primar unha sobre a outra simplemente polo seu valor estético, como aparentemente sucede.

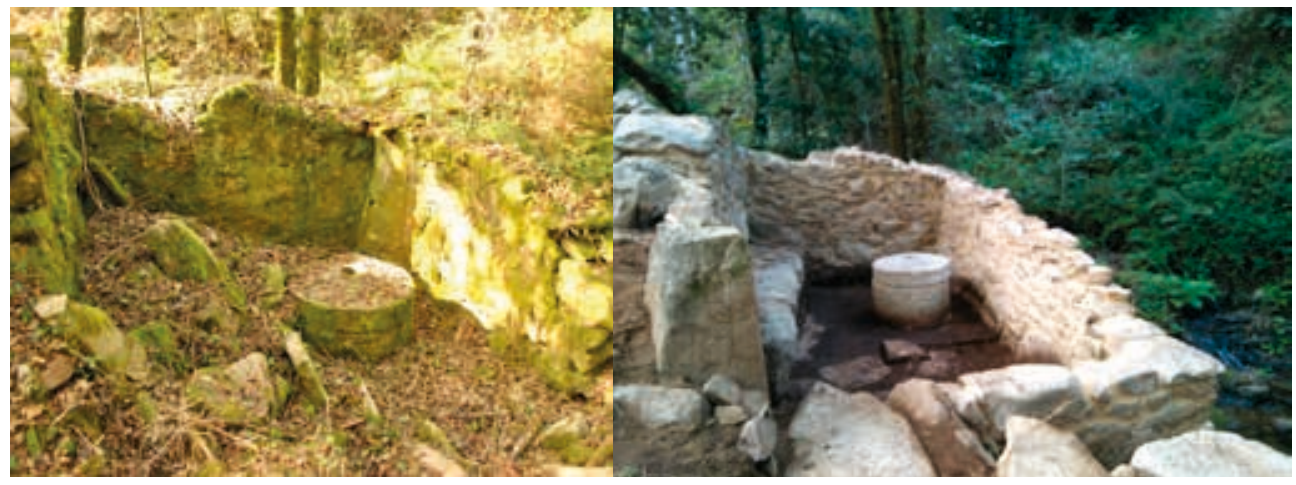

Consolidación de ruína de muíño, Salcedo (Pontevedra)

Os numerosos traballos con intención patrimonial en contextos hidráulicos destacan fronte ao tradicional abandono que adoitan sufrir outros bens do patrimonio coma, por exemplo, algúns elementos arquitectónicos ou arqueolóxicos. Poderiamos achacar esta tendencia das administracións a investiren maiores esforzos e contías económicas na conservación do patrimonio hidráulico ao valor estético que aínda conservan moitos dos nosos ríos, grazas aos seus 
bosques de ribeira, ben preservados. No entanto, este argumento desbotaría o escaso investimento noutros espazos de similares características estéticas e tamén con patrimonio singular. Talvez o feito de que moitas administracións, maioritariamente concellos, invistan nestes espazos se deba á aínda forte vinculación da nosa sociedade cos usos e costumes máis recentes na paisaxe tradicional. A conservación destes espazos é un recordo do valor funcional que, non hai tanto tempo, estas infraestruturas hidráulicas posuían, mais o valor que os espazos vinculados aos ríos teñen na actualidade xa non é tal.

Estes espazos xa non son necesarios desde unha óptica alimenticia, xa non se precisa que os muíños moian día e noite, posto que o millo galego xa non se destina a facer pan. A sociedade xa non precisa que os lavadoiros sexan espazos de aseo e comunicación social debido ás individualizadoras lavadoras. Por tanto, ante a ausencia de políticas que outorguen un novo valor a este patrimonio, son numerosos os casos en que volven ao abandono, incluso despois de cuantiosos investimentos.

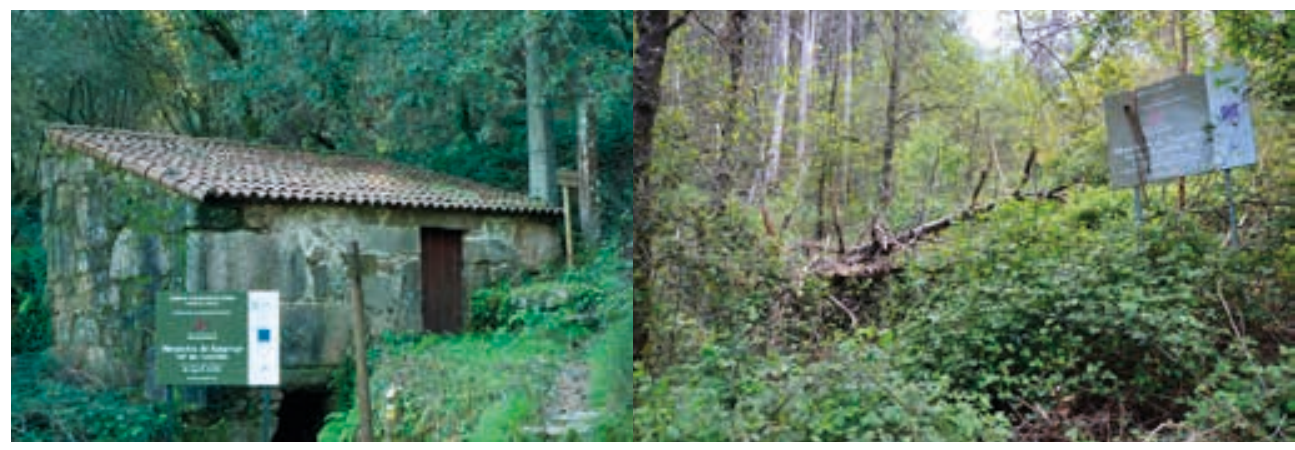

Resultado dos traballos do Obradoiro de emprego Val da Louriña. Imaxe esquerda: Wikiloc. Cartel e muíño abandonado tras o Obradoiro de emprego Val da Louriña II. Imaxe dereita: comarcasnarede.com

$\mathrm{O}$ valor patrimonial destes espazos presúmese, pero isto non significa que a sociedade sexa consciente ou que para mantelo non sexan necesarias políticas con certa constancia no tempo. Por un lado, como punto de partida para a súa conservación, é preciso coñecer en detalle o seu espazo e singularidades históricas. En moitos casos en que se realizaron tarefas de conservación, non existiu un proceso de documentación nin investigación desde unha perspectiva histórica. Adoita pensarse que todos os cursos fluviais se comportan historicamente da mesma 
maneira e esta afirmación utilízase como xustificación para a escasa investigación nesta temática. Por outro lado, faltan tamén obras de conxunto que poñan en común as ricas realidades de Galicia a respecto do patrimonio cultural hidráulico; obras que aglutinen investigacións locais excelentes, coma, por exemplo, a de Ramiro Barros Justo (2005) sobre os muíños das terras de Pontevedra, e fornezan unha perspectiva global galega.

Unha vez dado o primeiro paso de documentación e investigación histórica, cómpre divulgar o coñecemento adquirido a través dunha perspectiva vinculada á interpretación do patrimonio, unha disciplina comunicativa que busca transmitir ao visitante, sexa turista ou non, uns conceptos e significados do patrimonio cultural e natural co obxectivo de xerar nel sensacións e emocións que fomenten a apreciación e singularización dos bens en cuestión (Sam Ham e Jorge Morales, $\left.\mathrm{AIP}^{1}\right)$. Tanto a través de intérpretes do patrimonio coma por medio das infraestruturas de interpretación axeitadas, pódese conseguir o fin de vincular as comunidades locais co seu patrimonio, para que exerzan de primeiros custodios del.

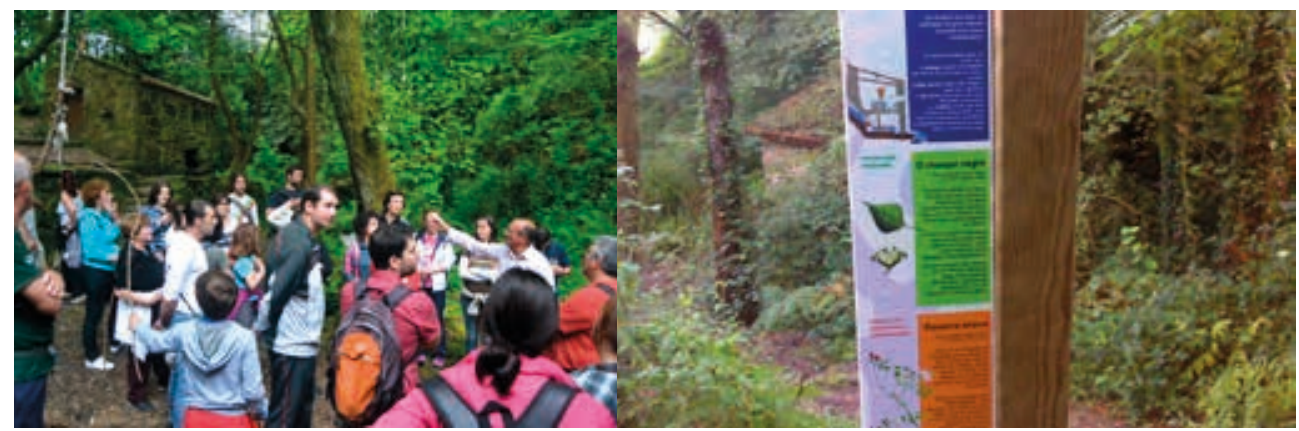

Visita guiada no río Frade (Bueu) e infraestrutura de interpretación do río Eifonso (Vigo)

As comunidades locais garanten a estabilidade de eventos vinculados aos usos tradicionais do río e do seu patrimonio, coma por exemplo o Encontro-Degustación do Millo Corvo, en Bueu, que xa vai pola súa XXI edición e divulga os valores da agricultura tradicional na figura dunha das variantes negras do millo americano, así como con exemplos de moenda no río Frade, en Meiro. Trátase dunha Festa de Interese Turístico de Galicia.

1 https://www.interpretaciondelpatrimonio.com/es/definiciones 


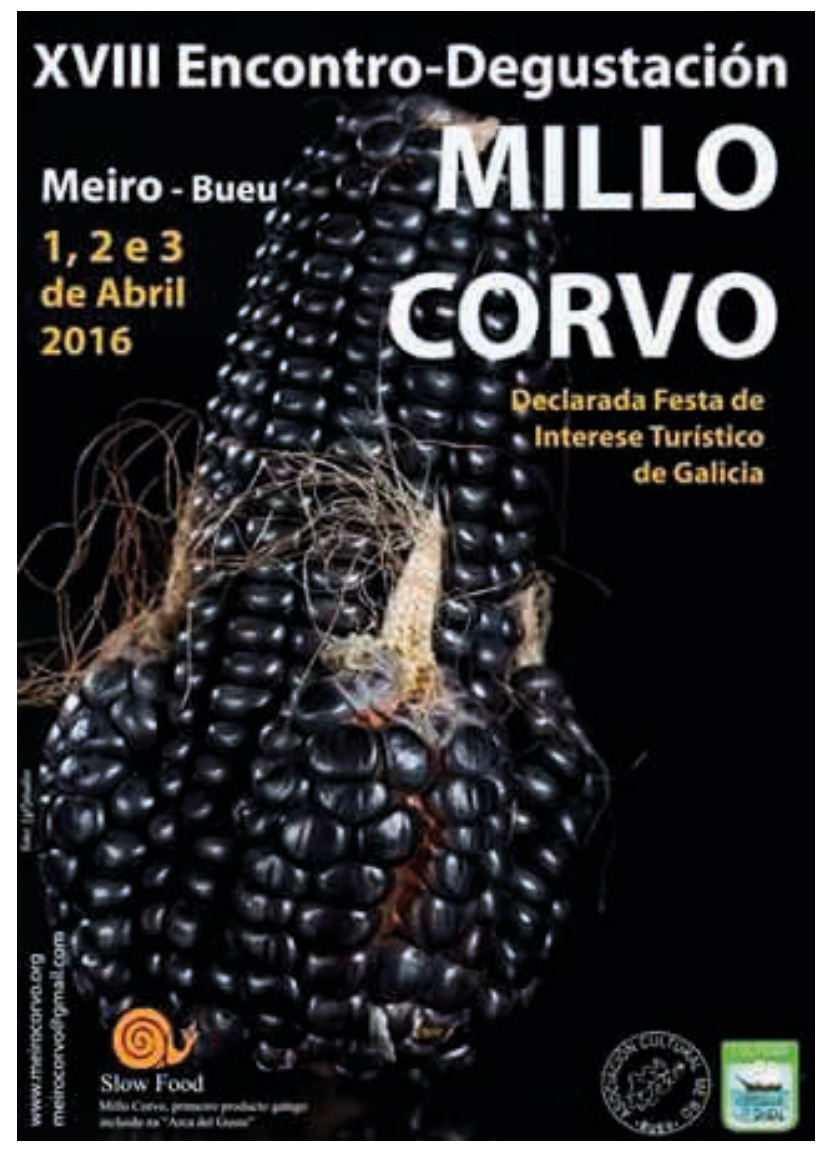

Cartel do XVIII Encontro-Degustación do Millo Corvo

A través do tipo de políticas anteriormente referidas, pódense fornecer valores que fomenten o aprecio e preocupación pola conservación do patrimonio, así como o lecer e a educación nestes espazos, xerando valores patrimoniais de tipo identitario, social ou económico.

Nunha sociedade para a cal os valores de uso do patrimonio cultural hidráulico xa están perdidos, pódense fornecer novos valores máis aló do estritamente patrimonial co obxectivo de garantir unha conservación e usos axeitados deste patrimonio. Existe a posibilidade de empregar actividades de corte máis clásico coma a divulgación e o uso destes espazos para lecer público, así como o emprego dalgún deles como establecementos de hostalaría, conservando as súas 
arquitecturas e os elementos tradicionais, que os contextualizan. Ademais, hai outros proxectos (que cómpre que conten coa autorización das administracións competentes) que poderían volver garantir uns ríos nos que os muíños e outros elementos, abandonados non hai moito tempo, recuperasen o seu uso hidráulico. É o caso da recuperación das numerosas pequenas centrais hidroeléctricas que ocupaban os nosos ríos e que incluso non eran máis grandes ca un muíño. A tecnoloxía actual, con pequenas turbinas que permiten xerar até $15 \mathrm{~kW}$, había posibilitar a recuperación de numerosos infernos de muínos desde unha óptica de conservación do patrimonio, pero tamén produtiva. Isto había permitir integrar os valores patrimoniais dos nosos ríos xunto cos valores ecolóxicos e económicos da sociedade actual, camiñando cara á preservación conxunta do patrimonio cultural e do natural, co obxectivo de conseguir ríos que nazan frades e morran bispos, non ao revés. 
UN RÍO QUE NACE FRADE E MORRE BISPO OU NACE BISPO E MORRE FRADE. APUNTAMENTOS SOBRE O PATRIMONIO CULTURAL HIDRÁULICO GALEGO

\section{REFERENCIAS BIBLIOGRÁFICAS}

Barrart i Hernández, Jospep / Josep Manuel Fullola i Pericot / María dels Ángels Petit i Mendizábal (1996): «El valor del patrimonio histórico», Complutum Extra, 6:2, 215-224.

Barros Justo, Ramiro (2005): Muiños de río das Terras de Pontevedra, Pontevedra, Servizo de Publicacións da Deputación de Pontevedra.

Bas López, Begoña (1991): Muiños de marés e de vento en Galicia, A Coruña, Fundación Pedro Barrié de la Maza.

CAAMAÑo SuÁREZ, Manuel (2003): As construccións da arquitectura popular: patrimonio etnográfico de Galicia, Santiago de Compostela, Consello Galego de Colexios de Aparelladores e Arquitectos Técnicos.

Miró Alaix, Manel (2000): «Construir el territorio museo: una propuesta para la gestión creativa del patrimonio cultural en áreas rurales», Actualidad Leader: Revista de Desarrollo Rural, 12, 8-9. 